\title{
MAGALLANES Y LOS RELATOS DE LA PRIMERA CIRCUNNAVEGACIÓN DEL MUNDO
}

\author{
Ximena Urbina \\ Pontificia Universidad Católica de Valparaíso
}

Resumen: Este número monográfico de Abriu (2019) quiere contribuir en los avances que, gracias a las celebraciones del quinto centenario del viaje de circunnavegación del mundo, la historiografía está llevando a cabo sobre una gesta y un personaje que fueron fundamentales para la historia de Occidente y del mundo, y que tuvieron enormes consecuencias para el conocimiento de una realidad que ineludiblemente tuvo que empezar a ser aprendida. Palabras Clave: Fernando de Magallanes; viaje de circunnavegación; descubrimientos ibéricos; literatura de viajes.

\section{Ferdinand Magellan and the Accounts of the First Circumanigation of the World}

AвSTRACT: This monographic issue of AвRIU (20I9) aims to contribute to the advances which, thanks to the five-hundredth anniversary of the voyage of circumnavigation of the world, are being made by historiography about a feat and a figure which were key for the history of the West and of the world, and which had enormous consequences for knowledge of a reality which inevitably had to start being learned.

KeYwords: Ferdinand Magellan; voyage of circumnavigation; Iberian discoveries; travel writing.

Son muchas las publicaciones, los seminarios y congresos, las celebraciones que ya desde el año 2017 se están llevando a cabo alrededor de la figura de Fernão de Magalhães y su viaje a las islas de las especias, y sin duda alguna van a ser más, dado el tiempo, desde I5I9 a 1522, que necesitó la esforzada armada de las Molucas en completar su odisea. Magallanes es el navegante más conocido de la historia, diríase que lo es más incluso que Cristóbal Colón, cuya hazaña fue igualmente inédita y deslumbrante, pero incomparable en esfuerzo y en sacrificio. La empresa de Magallanes significó un esfuerzo geográfico descomunal y también acarreó un sacrificio humano, tanto físico como moral, sin precedentes en la historia del viaje oceánico renacentista. También desde su origen creó un tenso conflicto geopolítico entre los dos reinos peninsulares que perduró largamente en el tiempo y tuvo consecuencias a escala planetaria.

Urbina, Ximena (2019). «Magallanes y los relatos de la primera circunnavegación del mundo». Abriu, 8, 9-13. ISSN: 2014-8526. e-ISSN: 2014-8534. DOI: 10.1344/abriuzorg.8.1. Received: : 30/4/2018. Accepted: 6/5/2019.

maria.urbina@pucv.cl | ORCID 0000-0002-3203-0269 Scopus 25825677800 | Pontificia Universidad Católica de Valparaíso (Chile) 
El nombre de Magallanes está unido a una proeza difícil de proyectar en el siglo XVI, incluso difícil ni siquiera de imaginar, como es la circunnavegación del globo terrestre. Sin embargo, el navegante portugués no completó esa vuelta al mundo que lleva su nombre porque murió durante la derrota del viaje. Al contrario de lo que instintivamente se suele pensar, el mundo no formaba parte del proyecto de Magallanes, sino la especia, la más lejana, la más exótica. Disgustado con el rey Manuel I de Portugal, cruzó en I5I7 la frontera para ofrecer al joven Carlos I un viaje destinado a probar que las islas Molucas, allí donde nacían el clavo y la nuez moscada, no se encontraban en la parte del hemisferio que, según el tratado de Tordesillas, pertenecía a Portugal, sino en el lado castellano. Su idea era llegar al mar de las especias siguiendo una ruta hacia el poniente y, tal como obligaba Tordesillas, regresar a Sevilla deshaciendo el rumbo emprendido. Las dramáticas vicisitudes del viaje obligaron a la nao Victoria, la única superviviente de las cinco que formaban la armada, a seguir navegando hacia el oeste y completar, así, la vuelta al mundo.

Ciertamente, cuando se piensa en Magallanes aparece instantáneamente la redondez del mundo, pero su aventura fue otra. En realidad, fueron dos, ambas fundamentales para entender la realidad del mundo: los dos grandes hitos del navegante portugués fueron el hallazgo del desolado estrecho en el meridión americano y la travesía por el mayor de los océanos del planeta, que a Magallanes le pareció pacífico. Pero esos dos grandes logros geográficos quedaron, si no eclipsados, sí empalidecidos por la heroicidad de la destartalada nao Victoria gobernada por el vasco Juan Sebastián Elcano.

La expedición de la armada de las Molucas es la que más relatos generó de todos los viajes marítimos de los siglos renacentistas, y de los veinticinco relatos conservados, once fueron escritos por testigos presenciales. A ellos cabe sumar un gran número de documentos de archivo que de manera directa o indirecta ofrecen detalles biográficos, político-económicos y geográficos que ayudan a completar la historia de aquel viaje. A ello ha dedicado muchos de sus trabajos José Manuel Garcia (miembro de la Academia Portuguesa da História y de la Academia de Marinha) para, metódicamente, ir creando un inventario sistemático de toda la documentación referente a Magallanes que se conserva en Portugal. Y resulta ser de mayor interés para intentar un acercamiento riguroso a una biografía que, como la de todos los héroes, es inexistente o insignificante o mancada de atención hasta que esos héroes no culminan sus heroicidades. En este sentido, el repaso detallado de la documentación referente a Magallanes demuestra el protagonismo que tuvo su experiencia en Oriente, 
previa al viaje a las Molucas bajo estandarte español para poder defender con solvencia su proyecto ante el rey Carlos. La biografía del Magallanes de la vuelta al mundo no existiría sin la biografía del Magallanes del viaje a la India.

Avanza un paso más el profesor Ruy Manuel Loureiro (director del Instituto Superior Manuel Teixeira Gomes, investigador del Centro de História Além-Mar [CHAM] en la Universidade Nova de Lisboa y miembro de la Academia da Marinha) al abordar el tipo de fuentes que pudo llegar a manejar Magallanes para, progresivamente, ir concretando la fiabilidad de una ruta occidental que llevase a Oriente que fuera defendible ante el Consejo Real español. No se conserva la posible biblioteca documental y cartográfica que sin duda llegó a poseer Magallanes, pero al reconstruir su biografía es posible crear un escenario bibliográfico que explique el acopio de informaciones, tanto orales como documentales, técnicas y gráficas, que el navegante fue recogiendo para afianzar su proyecto. Esa aproximación al espacio bibliográfico contemporáneo a Magallanes lo presenta como alguien extremadamente bien informado y muy pendiente de los documentos, impresos o manuscritos, que circulaban en la época, tanto en Oriente como en Portugal y España, sobre los espacios alcanzados por el viaje marítimo peninsular. Muchos de esos espacios, los orientales y los extremo-orientales, los había visto Magallanes con sus propios ojos.

También a los documentos, esa vez, los generados por el viaje magallánico, dedica su trabajo Mateo Martinić (profesor emérito de la Universidad de Magallanes y Premio Nacional de Historia, 2000), gran especialista en lo que él mismo llama el mundo del confín austral americano. Identifica en este artículo las fuentes primarias del primer cruce interoceánico — las escritas y las cartográficas - para informar con precisión de sus orígenes, destinatarios y el lugar donde se conservan (las que aún se conservan). Sin embargo, Martinić, gran conocedor de los espacios de la Magallania, ofrece aquí nuevos aportes al advertir que en uno de los mapas, el portulano de 1562 del cartógrafo mallorquín Bartolomé Oliva, del Atlas Náutico del Mundo que el papa Francisco donó a la Pontificia Universidad Católica de Chile con ocasión de su visita en enero de 20ı8, había una anotación marginal en la parte meridional de Sudamérica que demuestra que Oliva tuvo en sus manos un derrotero hecho por el propio Magallanes del que hasta ahora no se tenía noticia. Esta es una prueba de que el acervo documental original de la expedición magallánica que se ha conservado hasta nuestros días es solo una parte menor de lo que en la realidad debió ser en su hora. El autor se pregunta por estos documentos, olvidados o desa- 
parecidos, y presume que debieron haberse incautado por los portugueses en Tidor, enviados a Portugal y ocultados celosamente. Al relacionar documentos y cartografía, este artículo constituye un aporte genuino a la reconstitución del catastro de las fuentes del cruce magallánico y a la interpretación de sus silencios y de sus expresividades.

El artículo de Clayton McCarl (profesor de la Universidad de North Carolina) se centra en los caminos que siguió el testimonio de Antonio Pigafetta, desde los primeros manuscritos redactados en Europa (entre I522 y I524) y la primera impresión, en París (Le voyage et navigation), en I525. Esa edición y aquellos manuscritos fueron fuentes de sucesivas ediciones, que el autor reconstruye con detalle desde esos años y hasta nuestros días, para considerar, además, las variaciones del texto, los caminos seguidos y sus estudios críticos. En suma, se trata del historial de publicación del escrito de Antonio de Pigafetta sobre el primer viaje alrededor del mundo, lo que contribuye no solo a conocer mejor la trayectoria del autor como testigo, sino que también realiza aportaciones a un tipo importante de estudios, como es el de las tradiciones bibliográficas.

Y cierra este número 8 de la revista ABriu un trabajo que solo un investigador con profunda formación filológica y gran conocedor de las culturas y las lenguas orientales podría llevar a cabo. Luís Filipe F. R. Thomaz (profesor emérito y honoris causa de la Universidade Nova de Lisboa y fundador del Instituto de Estudos Orientais de la Universidade Católica Portuguesa) también dedica su artículo al más rico y fidedigno de los textos que relatan el viaje de Magallanes que termina por ser el de la vuelta al mundo, aquel escrito por el aventurero Antonio Pigafetta, pero se centra en lo que lo hace peculiar y lo diferencia de otros documentos testimoniales. Pigafetta incluyó pequeños glosarios de cuatro lenguas diferentes habladas por las comunidades que los navegantes fueron encontrando: uno muy breve, de ocho vocablos de los indios brasileños de la región de Guanabara; otro más extenso de la región patagona; un tercer glosario de la lengua austronésica hablada en Cebú, en las actuales Filipinas, y, por último, una cuarta relación mucho más extensa, de cuatrocientas veintiséis palabras en la lengua vehicular y de comercio que era el malayo en toda la Insulindia. Las meticulosas notas a pie de página que constituyen el estudio de este glosario no solo demuestran que Pigafetta era alguien verdaderamente curioso, sino que también estaba dotado de un excelente oído, y, a su vez, el conjunto del glosario no solo informa sobre la búsqueda detallada de informaciones, sobre todo, de interés económico, sino también 
sobre otros aspectos más triviales y espontáneos de la vida cotidiana que importaban a los navegantes de hace quinientos años.

Este número monográfico de AвRIu ha querido contribuir así en los avances que, gracias a las celebraciones del quinto centenario del viaje de circunnavegación del mundo, la historiografía está llevando a cabo sobre una gesta y un personaje que fueron fundamentales para la historia de Occidente y del mundo, y que tuvieron enormes consecuencias para el conocimiento de una realidad que ineludiblemente tuvo que empezar a ser aprendida. 